\title{
A Kinetic Study of Anaerobic Biodegradation of Food and Fruit Residues during Biogas Generation Using Initial Rate Method
}

\author{
William Wanasolo, Samwel Victor Manyele, John Makunza \\ Department of Chemical and Mining Engineering, College of Engineering and Technology, \\ University of Dar es Salaam, Dar es Salaam, Tanzania \\ Email: wanasolo@gmail.com, smanyele@udsm.ac.tz,makunzaj@gmail.com
}

Received May 23, 2013; revised June 23, 2013; accepted July 1, 2013

Copyright (C) 2013 William Wanasolo et al. This is an open access article distributed under the Creative Commons Attribution License, which permits unrestricted use, distribution, and reproduction in any medium, provided the original work is properly cited.

\begin{abstract}
A kinetic study of biogas production from Urban Solid Waste (USW) generated in Dar es Salaam city (Tanzania) is presented. An experimental bioreactor simulating mesophilic conditions of most USW landfills was developed. The goal of the study was to generate the kinetic order of reaction with respect to biodegradable organic waste and use it to model biogas production from food residues mixed with fruit waste. Anaerobic biodegradation was employed under temperature range of $28^{\circ} \mathrm{C}-38^{\circ} \mathrm{C}$. The main controls were leachate recirculation and $\mathrm{pH}$ adjustments to minimize acid inhibitory effects and accelerate waste biodegradation. The experimental setup was comprised of three sets of bioreactors. A biodegradation rate law in differential form was proposed and the numerical values of kinetic order and rate constant were determined using initial rate method as 0.994 and $0.3093 \mathrm{~mol}^{0.006} \cdot$ day $^{-1}$, respectively. Results obtained were consistent with that found in literature and model predictions were in reasonable agreement with experimental data.
\end{abstract}

Keywords: Urban and Municipal Solid Waste; Biogas Production; Anaerobic Biodegradation; Mesophilic Conditions; Order of Reaction; Kinetic Model; Initial Rate Method; Renewable Energy; Bioreactor; Landfill; Biodegradable Organic Waste

\section{Introduction}

One of the main global challenges of the $21^{\text {st }}$ Century is the rapidly growing energy demand where a high percentage is met by supplies from fossil fuels. It has been reported that during this century energy demand will increase by a factor of two or three [1]. The use of fossil fuels contributes significantly to the rising concentrations of greenhouse gases (GHGs) in the stratosphere resulting in global warming. The quest for alternative energy sources has become inevitably important with renewable energy sources as the most credible alternative. Renewable energy is energy derived from natural processes such as sunlight and wind that are replenished at a higher rate than they are consumed. Solar, wind, geothermal, hydro, biomass and biogas are common examples of renewable energy [2]. It has been proposed that in the next few decades, bio-energy will be the most significant renewable energy source compared to fossil fuels [3]. This shows the increasing attention towards use of renewable energy for solving global energy needs and environmental problems. In Tanzania and most African countries, biogas is the common type of renewable energy in use. It is produced mainly from animal waste excreta. No attempt has been made to produce biogas from Urban Solid Waste (USW) in this region. In addition, the science behind biogas production rates from USW is yet to be studied. Biogas production from USW elsewhere in the world has been studied. However, the kinetic orders have always been assumed and applied retrospectively in researches related to the bioconversion of Solid Waste Organic Matter (SWOM). This paper focuses on kinetics by determining the kinetic order of the biodegradation process during biogas generation, using initial rate method. The study employed wet digesters to ferment food residues mixed with fruit waste obtained from staff Canteens and student Cafeterias at the University of Dar es Salaam (UDSM) in Tanzania.

\section{Literature Review}

\subsection{Biogas Potential}

There is great potential for biogas generation from Solid 
Waste (SW). Elango, Pulikesi, Baskaralingam, Ramamurthi and Sivanesan 2007 [4] generated biogas from Municipal Solid Waste (MSW) enhanced by addition of domestic sewage. The amount of biogas production reported was $0.36 \mathrm{~m}^{3} / \mathrm{kg}$ of volatile solids (VS) added per day at optimal organic loading rate of $2.9 \mathrm{~kg} \mathrm{VS} / \mathrm{m}^{3} /$ day and the biogas produced during anaerobic digestion had methane composition in the range of $68 \%-72 \%$. Rao, Baral, Dey and Mutnuri 2010 [5] estimated the bio-energy potential of MSW, crop remains and farm waste, wastewater sludge, animal refuse, industrial waste in India to be $40,734 \mathrm{Mm}^{3} /$ year. Furthermore, it has been reported that USW contains an easily biodegradable organic fraction of up to $40 \%$ [6]. Methane generated from fermentation of sewage sludge, Organic Fraction of Municipal Solid Waste (OFMSW) was investigated and biogas obtained contained about $60 \%$ methane gas. The biogas productivity varied between 0.4 and $0.6 \mathrm{dm}^{3} / \mathrm{g}$. All these show that there is a high potential of biogas generation from anaerobic biodegradation of SW, especially, SWOM.

The prospects of biogas generation from anaerobic digestion of other waste of biomass elsewhere have also been studied. In a comparative study of digestion of sewage sludge (SS) and OFMSW, the cumulative biogas production for SS was found to be lower than that for OFMSW [7]. MSW has been one of the most potential feedstock for many anaerobic digestion processes $[8,9]$. These studies also show a high prospect of generating biogas from SWOM.

\subsection{Advantages of USW}

The availability and abundance of SWOM in urban centers is of great advantage for biogas generation. The bioconversion of USW process is non-polluting and environmentally friendly, involves less capital investment in relation to other renewable energy resources such as hydro-power, solar and wind energy. Also, biogas is available as a domestic resource in rural areas, which makes it not subject to world price fluctuations and unpredictable supplies of conventional fuels [5].

\subsection{Factors Affecting Biodegradation Process}

Properties of the raw USW particularly the amount of biodegradable matter affect its biodegradability. Wang 2004 [10] classified the biodegradable fraction as rapidly, moderately and slowly biodegradable organic matter basing on physical parameters of solubility and particulate level and biological factor of presence and type of microbes. There are many other factors that influence biodegradation process among which are retention time, recycle leachate, $\mathrm{pH}$, organic loading rates and substrate type. It has been found that the mean daily biogas pro- duction and yield per unit weight of waste increased for high retention time. The mean daily biogas yield per unit waste was $51.6 \mathrm{~L}$ biogas $/ \mathrm{kg}$ day for high retention time compared to $48.7 \mathrm{~L}$ biogas/kg day for low retention time, attributed to longer digestion period [11]. Nevertheless, the volume of biogas generated per unit weight of partially solid fruit waste combined with assimilated sludge at shorter retention time had higher biogas production compared to that produced with high retention time but without recycled digested sludge [11]. This shows that recycle digested sludge influence biogas production more than retention time. In addition, several authors found that the time required for complete digestion was large because the SW dissolution and its hydrolysis to lowermolecular-weight compounds were the rate limiting steps in the anaerobic digestion process $[5,12,13]$. Furthermore, the stability of the anaerobic process and the rate of biogas production depended on organic loading rates [5]. It was also shown that anaerobic digestion became more stable when a variety of substrates were applied [7]. In the general sense, during anaerobic digestion, microorganisms utilize carbon 25 - 30 times faster than nitrogen [14]. Co-digestion improved nutrient balance by adding large quantities of carbon being readily biodegradable resulting in enhanced biogas yields [7].

One of the important parameters affecting OFMSW biodegradation is moisture content, which can be regulated by way of leachate recirculation [15]. The idea of enhancing refuse decomposition by addition of water and/or re-circulating leachate was first proposed several decades ago [16]. Leachate re-circulation promotes biodegradation process because liquid movement spreads out the microbial inoculum, mitigates local nutrient shortages and offsets potential toxins. However, in the absence of active acetogenic and methanogenic populations, re-circulated leachate may cause an accumulation of volatile fatty acids (VFA). Sosnowski, Klepacz-Smolka, Kaczorek and Ledakowicz 2008 [7] found that accumulation of VFA caused $\mathrm{pH}$ decrease and strongly inhibited subsequent biogas production. A combination of leachate recirculation and $\mathrm{pH}$ adjustment can minimize the inhibitory effects of acid accumulation and accelerate the rate of SW biodegradation. Leachate recycle is therefore an important component in biogas production from USW leading to its $\mathrm{pH}$ recovery. This technique was employed in the present research

\subsection{Compositing Kinetics}

Composting (that is, biodegradation in the presence of oxygen) has gained an important role in USW management. Composting kinetics has been investigated recently by many researchers to describe the decomposition of organic wastes. For example, the kinetics of co-composting of Rose processing waste and OFMSW under 
aerobic conditions was evaluated and the results showed first order kinetics as the best fitting kinetic model [13]. No model has been proposed to fix the kinetic orders for anaerobic processes of USW. Several other researchers used first order kinetic models to describe different biodegradation processes. Kirchmann and Bernal, 1997 [17] applied first-zero-order model for aerobic biodegradation of different material types such as cattle dung, pig dung, and sewage sludge-cotton waste mixture. Paredes, Bernal, Cegarra and Roig, 2002 [18] found that organic matter losses followed a first-order kinetic equation for aerobic biodegradation of olive mill wastewater sludge. Baptista, Antunes, Gonçalves, Morvan and Silveira, 2010 [19] investigated the kinetics of solid waste compositing based on VS change and the experimental data were fitted with a first-order kinetic model, and a rate constant of composting under optimum conditions was obtained.

\subsection{Modeling Kinetics}

Modeling has often been used as the main tool in the study of composting as well as anaerobic biodegradation processes, frequently with the aim of optimizing the design and operation of full-scale plant. Such studies yielded models such as the Anaerobic Digestion Model No. 1 (ADM 1) [20] and several other mathematical models. However, few studies have applied such models to full scale plants [19]. Besides, Kinetic models for anaerobic digestion of organic substrates were derived for substrate utilization and methane production [21]. The model equations considered hydrolyzed products as limiting nutrients for microbial growth and biogas production according to Monod kinetics. Additionally, a kinetic model for investigation of the anaerobic digestion of wastewater generated from orange rind pressing during orange juice making was proposed basing on the experimental results determined at mesophilic conditions [22]. Monod type kinetic models were also widely used to describe process kinetics of anaerobic digesters successfully $[15,23]$. Although there was some success in applying Monod type kinetics to the anaerobic process, some researchers found it difficult to apply them for their systems [15,23]. Furthermore, a two-stage model combining zero and first order kinetics based on enzyme reaction and Monod type micro-organism growth rate equation was proposed and developed for handling hospital waste biodegradation in landfills [10]. This model successfully predicted both the cumulative biogas production and its rate. It assumed zero order kinetics at the start of the process followed by a first order kinetics with respect to biodegradable organic carbon. The model did not differentiate between the time when the zero order ends and the start of first order and therefore it was used ambiguously. Also, García-Ochoa, Santos, Naval, Guar- diola and Lopez, 1999 [12] developed two separate kinetic models to explain the anaerobic digestion of livestock refuse. This model replicated the experimental data obtained for cow manure anaerobic digestion with more accuracy.

In this study, the simulation model developed by Wang, 2004 [10] was adopted and modified in derivation. It was assumed that the biodegradation of organic matter depended on both the amount of biodegradable organic matter present and moisture content as the primary limiting factors. The model selection was influenced by the strength of experimental support and mathematical derivations.

\section{Methods and Equipment}

\subsection{Design Features of Experimental Setup}

The experimental set-up comprised of three sets of bioreactor cells shown in Figure 1. The first set had three cells in series labeled $\mathrm{BA}_{1}, \mathrm{BA}_{2}$ and $\mathrm{BA}_{3}$. The second had two: $\mathrm{BB}_{1}$ and $\mathrm{BB}_{2}$ and the third had one, $\mathrm{BC}_{1}$. Each of these cells was of volume 3 liters. Leachate was collected in tanks $\mathrm{Lt}_{1}, \mathrm{Lt}_{2}$ and $\mathrm{Lt}_{3}$ and recycled using pumps $\mathrm{P}_{1}, \mathrm{P}_{2}$ and $\mathrm{P}_{3}$, respectively. The pipe system was made of IPS material to limit corrosion and contamination. Biogas was tapped to the gas measuring device $\mathrm{LI}_{1}$ connected to a calibrated manometer $\mathrm{LI}_{2}$. Using control valve $\mathrm{CV}_{1}$, the gas volume was measured at regular time intervals and collected in gas collection bag GB. In general a batch type of bioreactors in series was operated at temperature range of $28^{\circ} \mathrm{C}-38^{\circ} \mathrm{C}$.

\subsection{Data Collection}

Three batches of 12.0, 12.9 and $13.2 \mathrm{~kg}$ were prepared at three different times. Batch one of $12.0 \mathrm{~kg}$ was distributed in six bioreactor cells of Figure 1. Three experiments of weight $\left(M_{w}\right)=6 \mathrm{~kg}$ (set one), $4 \mathrm{~kg}$ (set two) and $2 \mathrm{~kg}$ (set three) each were carried out simultaneously over a period of about one week. This was repeated for batches two and three. All the batches comprised of food residues, fruit waste and non biodegradables shown in Figure 2.

The SW was sorted and categorized as biodegradable food residues (BFR), biodegradable fruit waste (BFW) and non-biodegradable waste (NBW). This categorization is shown in Table 1 while Table 2 shows the moles of biodegradable matter of batches one, two and three. In the first batch, the different categories of waste were mixed and distributed in the six bioreactor cells each taking about $2 \mathrm{~kg}$. Water of $\mathrm{pH} 7.04$ and microbial inoculum were added at temperature of $32^{\circ} \mathrm{C}$. The bioreactors were then completely sealed to avoid oxygen interference and allow mesophilic biodegradation process to take place. The biogas volume measurements were done 


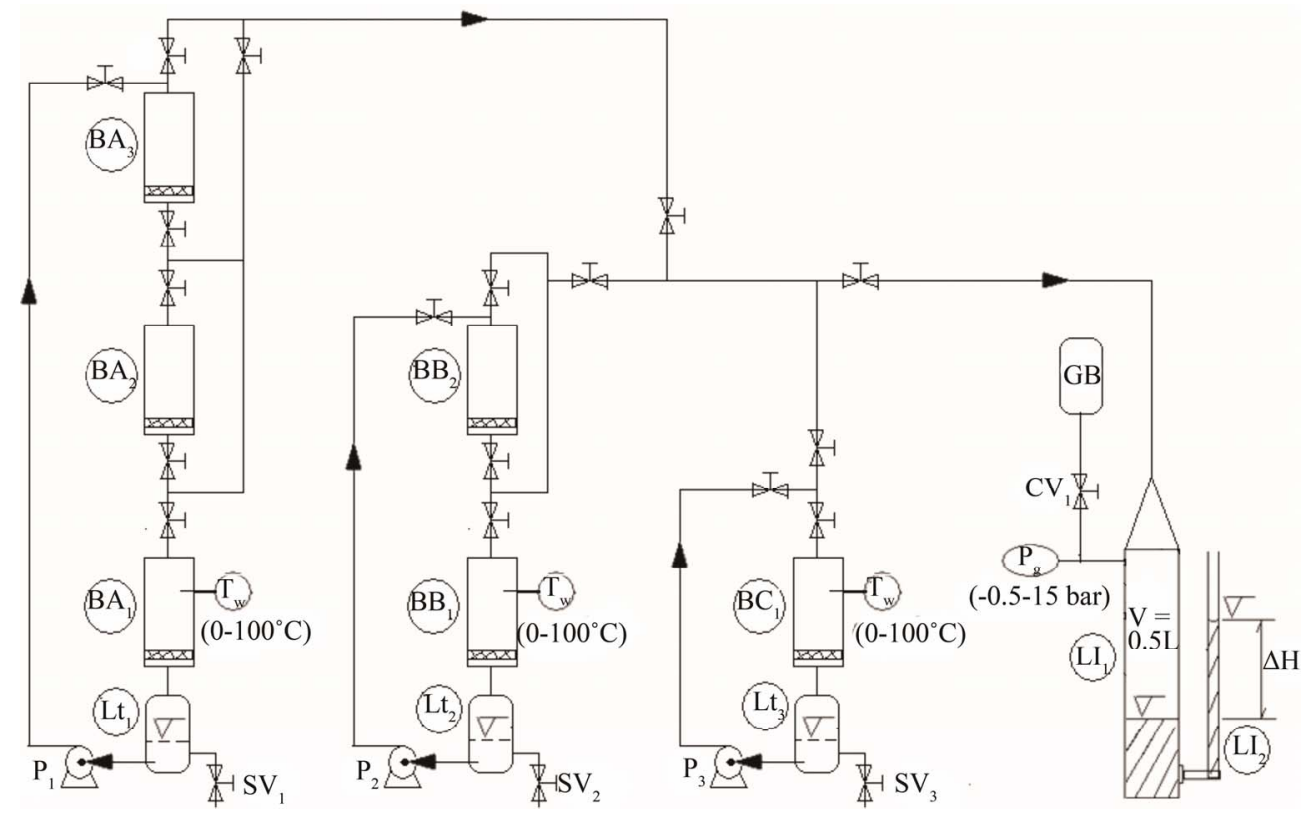

Figure 1. Experimental Setup: $\left(L_{t}=\right.$ Leachate collection tank $(10 \mathrm{~L}), \mathrm{P}=$ Leachate circulation pump $(0.5 \mathrm{Hp}), \mathrm{B}=\mathrm{Bioreactor}$ cells $(3 \mathrm{~L}), \mathbf{L I}_{1}=$ Level Indicator (tank), $\mathbf{L I}_{2}=$ Level Indicator (Manometer), $\mathbf{C V}_{1}=$ Volume control valve and GB $=\mathrm{Gas}$ collection bag).
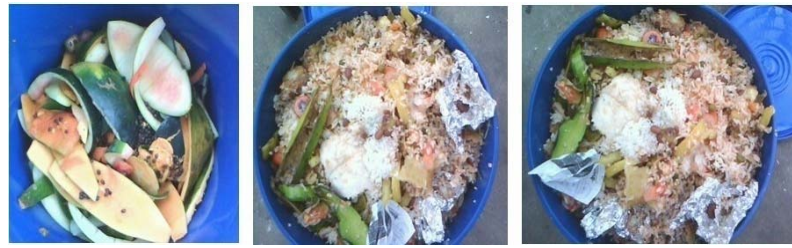

Figure 2. Food residues and fruit waste from USDM.

Table 1. Percent composition of food residues mixed with fruit waste.

\begin{tabular}{cccc}
\hline Type of waste & \multicolumn{3}{c}{ Batch } \\
\hline & One & Two & Three \\
BFR & $52.50 \%$ & $53.49 \%$ & $61.36 \%$ \\
BFW & $45.80 \%$ & $44.19 \%$ & $37.88 \%$ \\
NBW & $1.70 \%$ & $2.32 \%$ & $0.76 \%$ \\
Total & $100 \%$ & $100 \%$ & $100 \%$ \\
\hline
\end{tabular}

Table 2. Initial moles of biodegradable waste, $\boldsymbol{n}_{b i}$

\begin{tabular}{cccc}
\hline Experimental setup & Batch one & Batch two & Batch three \\
\hline 1 & 0.4913 & 0.5246 & 0.5578 \\
2 & 0.3275 & 0.3497 & 0.3718 \\
3 & 0.1638 & 0.1749 & 0.1859 \\
\hline
\end{tabular}

daily for a period of 4 days. After 2 days of biodegradation, the $\mathrm{pH}$ of the reacting matrix dropped significantly overnight and during the day time to below $\mathrm{pH}$ of 4.5 and the biodegradation process ceased, indicated by lack of liquid level displacement at $\mathrm{LI}_{2}$. The $\mathrm{pH}$ was restored to the range of 5.50 to 8.00 by adding leachate after adjusting using Kaoline and also by direct additions of sodium hydroxide solution. Pumps were switched off to avoid pump pressure interference with biogas pressure during volume measurements. The pressure of the system was brought to zero or atmospheric pressure which was the reference point for pressure and volume measurements.

\subsection{Model Formulation}

Model formulation was based on assumption that the biodegradation reaction was carried out at standard pressure (atmospheric pressure of 1 atmosphere). However, the temperature deviated slightly (mesophilic) from standard conditions. Therefore, the conditions of biodegradetion process were approximated to standard temperature and pressure. From Avogadro's law, the volume of 1 mole of gas at standard temperature and pressure (STP) is $22,400 \mathrm{ml}$. Therefore, the number of moles of biogas produced in an experiment, $n_{g}$, can be determined as per Equation (1), where $V_{b}=$ volume of biogas produced in $\mathrm{ml}$.

$$
n_{g}=\frac{V_{b}}{22400}
$$

Using Equation (1), the biogas production rate in 2 minutes sampling time for batches one, two and three experiments were determined as summarized in Tables $3-5$, respectively. 


\subsection{Order of Reaction and Rate Constant}

The general biochemical equation for biodegradation of organic matter can be written as per Equation (2).

$$
\alpha A+\beta B \rightarrow r C+s D+t E+u F
$$

where $A, B, C, D, E$ and $F$ are biodegradable organic matter, moisture, methane, carbon dioxide, ammonia and biomass, respectively; $\alpha, \beta, r, s, t$ and $u$ are stoichiometric coefficients.

The rate of biogas production is given by Equation (3):

$$
r=\frac{\mathrm{d} C}{\mathrm{~d} t}=-k A^{p} B^{q}
$$

where $p$ and $q$ were the proposed orders of reaction to be determined and which are not necessarily equal to the stoichiometric coefficients of reactants in Equation (2). The biogas produced was assumed to be a mixture of methane, carbon dioxide and ammonia in Equation (2). Equation (3) is the proposed biodegradation rate law

Table 3. Batch one gas rate $(\mathrm{mol} / \mathrm{min})$ at $2 \mathrm{~min}$ sampling time.

\begin{tabular}{cccc}
\hline Residence & Experiment 3 & Experiment 2 & Experiment 1 \\
\hline Time (days) & $M_{w}=2 \mathrm{~kg}$ & $M_{w}=4 \mathrm{~kg}$ & $M_{w}=6 \mathrm{~kg}$ \\
1 & $5.208 \times 10^{-5}$ & $1.105 \times 10^{-4}$ & $1.548 \times 10^{-4}$ \\
2 & $4.464 \times 10^{-5}$ & $8.929 \times 10^{-5}$ & $1.289 \times 10^{-4}$ \\
3 & $4.911 \times 10^{-5}$ & $1.049 \times 10^{-4}$ & $1.406 \times 10^{-4}$ \\
4 & $4.688 \times 10^{-5}$ & $8.482 \times 10^{-5}$ & $1.384 \times 10^{-4}$ \\
\hline
\end{tabular}

Table 4. Batch two gas rate $(\mathrm{mol} / \mathrm{min})$ at $2 \mathrm{~min}$ sampling time.

\begin{tabular}{cccc}
\hline Residence & Experiment 3 & Experiment 2 & Experiment 1 \\
\hline Time (days) & $M_{w}=2.15 \mathrm{~kg}$ & $M_{w}=4.30 \mathrm{~kg}$ & $M_{w}=6.45 \mathrm{~kg}$ \\
1 & $3.311 \times 10^{-5}$ & $6.423 \times 10^{-5}$ & $1.026 \times 10^{-5}$ \\
2 & $3.571 \times 10^{-5}$ & $6.679 \times 10^{-5}$ & $1.111 \times 10^{-4}$ \\
3 & $3.823 \times 10^{-5}$ & $7.422 \times 10^{-5}$ & $1.199 \times 10^{-4}$ \\
4 & $2.065 \times 10^{-5}$ & $4.088 \times 10^{-5}$ & $5.802 \times 10^{-5}$ \\
\hline
\end{tabular}

Table 5. Batch three gas rate $(\mathrm{mol} / \mathrm{min})$ at $2 \mathrm{~min}$ sampling time.

\begin{tabular}{cccc}
\hline Residence & Experiment 3 & Experiment 2 & Experiment 1 \\
\hline Time (days) & $M_{w}=2.25 \mathrm{~kg}$ & $M_{w}=4.50 \mathrm{~kg}$ & $M_{w}=6.75 \mathrm{~kg}$ \\
1 & $1.53 \times 10^{-5}$ & $3.05 \times 10^{-5}$ & $4.58 \times 10^{-4}$ \\
2 & $3.91 \times 10^{-5}$ & $7.81 \times 10^{-5}$ & $1.17 \times 10^{-4}$ \\
3 & $4.13 \times 10^{-5}$ & $8.26 \times 10^{-5}$ & $1.24 \times 10^{-4}$ \\
4 & $3.79 \times 10^{-5}$ & $7.59 \times 10^{-5}$ & $1.14 \times 10^{-4}$ \\
\hline
\end{tabular}

governing the biodegradation of organic matter contained in USW. The equation is in differential form where the moles of organic matter is represented by $A$ and that of moisture by $B$. The exact numerical value of $p$ was determined from the experimental data using initial rate method. The rate of organic matter consumption can be expressed as the rate of biogas production and it is equal to the rate of decomposition of substrate organic matter, $A$, and that of moisture as summarized in Equation (4).

$$
r=+\frac{\mathrm{d} C}{\mathrm{~d} t}=-\frac{\mathrm{d} A}{\mathrm{~d} t}=-\frac{\mathrm{d} B}{\mathrm{~d} t}
$$

The value of $p$ was established by making the amount of organic matter, $A$, a limiting factor while moisture was present in excess. All other factors namely temperature, $\mathrm{pH}$, nutrient level, micro-organisms, etc., were kept at optimal quantities, and assumed to be constant. Using any of Equation (3) or (4) the biodegradation rate law is reduced to Equation (5), i.e.,

$$
r=-k A^{p}
$$

Based on data from the nine experiments of batches one, two and three (Tables 3-5) and applying Equation (5) gives a set of three equations with two unknowns $p$ and $k$, solutions of which yield three values of $p$. Using the arithmetic average value of $p$, three values of $k$ were also determined. Hence the arithmetic average values of $p$ and $k$ for the three experiments of batch one at residence time of 1 day were determined. This process was repeated for residence times of 2, 3, and 4 days for batch one and for batches two and three. Results are as shown in Table 6.

\subsection{Model Equations}

Model equations were determined after evaluating the values of $p_{a v}$, and $k_{a v}$. Thus, from Equation (5):

$$
r=\frac{\mathrm{d} A}{\mathrm{~d} t}=-k_{a v} A^{p}
$$

Substituting for $p=p_{a v}=0.994$ into Equation (6) and integrating between limits $t=(0, t)$ and $A=\left(A_{o}, A_{t}\right)$ leads to Equation (7).

$$
A_{t}=\left[A_{o}^{0.006}-0.006 k_{a v} t\right]^{166.67}
$$

Equation (7) is the solution to Equation (6). $A_{t}$ is the $\mathrm{kmol}$ of biodegradable organic matter remaining after time $t, A_{o}$ is the initial kmol of biodegradable organic matter and $k_{a v}$ is the average rate constant in $\mathrm{kmol}^{0.006}$. $\min ^{-1}$. Differentiating Equation (7) with respect to time, gives the rate of biodegradation in $\mathrm{kmol} / \mathrm{min}$ at any time, $t$, in minutes as per Equation (8):

$$
\frac{\mathrm{d} A_{t}}{\mathrm{~d} t}=-k_{a v}\left[A_{o}^{0.006}-0.006 k_{a v} t\right]^{165.67}
$$

Equation (8) is the model equation for rate of reaction 
Table 6. Arithmetic average rate orders and rate constants.

\begin{tabular}{cccccccc}
\hline$R_{t}$ (days) & \multicolumn{3}{c}{ kinetic order, $p$} & \multicolumn{4}{c}{ Rate constant, $k$} \\
\hline & $\begin{array}{c}\text { Batch } \\
\text { one }\end{array}$ & $\begin{array}{c}\text { Batch } \\
\text { two }\end{array}$ & $\begin{array}{c}\text { Batch } \\
\text { three }\end{array}$ & $\begin{array}{c}\text { Batch } \\
\text { one }\end{array}$ & $\begin{array}{c}\text { Batch } \\
\text { two }\end{array}$ & $\begin{array}{c}\text { Batch } \\
\text { three }\end{array}$ \\
1 & 0.969 & 1.047 & 0.985 & 0.00031 & 0.0002 & 0.00008 \\
2 & 0.957 & 1.063 & 0.963 & 0.00026 & 0.00021 & 0.00020 \\
3 & 0.925 & 1.061 & 0.947 & 0.00029 & 0.00023 & 0.00021 \\
4 & 1.016 & 0.930 & 1.065 & 0.00026 & 0.00012 & 0.00021 \\
Average & 0.967 & 1.025 & 0.990 & 0.00028 & 0.00019 & 0.00018 \\
$\begin{array}{c}\text { Overall } \\
\text { average }\end{array}$ & 0.994 & & & $0.00022 \mathrm{~mol}^{0.006} \cdot \mathrm{min}^{-1}$ \\
\hline
\end{tabular}

$R_{t}=$ residence time in days.

in terms of the remaining biodegradable organic matter $A_{t}$, at time $t$ (minutes). The kmol of biodegradable organic matter that was biodegraded after time $t$ (minutes), denoted by $\Delta A_{o t}$, can be determined as per Equation (9):

$$
\Delta A_{o t}=A_{o}-A_{t}
$$

According to Wang 2004 [10], this corresponds to the $\mathrm{kmol}$ of biogas produced in time $t$ ( $\mathrm{min})$. From Avogadro's law, the volume of 1 mole of gas at standard temperature and pressure is 22.4 liters $\cdot \mathrm{mol}^{-1}$. This law applies to atomic and gaseous species. That is, 1 mole of atomic species occupies 22.4 liters $\cdot \mathrm{mol}^{-1}$ of volume. Since 1 mole of biodegraded carbon atoms corresponds to 1 mole of biogas produced, then 1 mole of biodegraded carbon atoms corresponds to 22.4 liters of biogas. Thus, $\left(A_{o}-\right.$ $\left.A_{t}\right) \mathrm{kmol}$ of biodegraded carbon corresponds to $22400 \times$ $\left(A_{o}-A_{t}\right) \times 10^{3}$ liters of biogas. If this volume of biogas produced in time $t$ is denoted by $D_{t}$, then:

$$
D_{t}=22400\left(A_{o}-A_{t}\right)
$$

Substituting for $A_{t}$ from Equation (7) into Equation (10) leads to:

$$
D_{t}=22400\left[A_{0}-\left(A_{0}^{0.006} 0.006 k_{a v} t\right)^{166.67}\right]
$$

Equation (11) is the model equation for the volume of gas produced in sampling time $t$ (minutes). The rate of gas production in sampling time $t$ is obtained by differentiating Equation (11) which gives Equation (12).

$$
\frac{\mathrm{d} D_{t}}{\mathrm{~d} t}=22400 k_{a v}\left(A_{o}^{0.006}-0.006 k_{a v} t\right)^{165.67}
$$

Equation (12) is the kinetic model equation for biogas production rate in $\mathrm{dm}^{3} \cdot \mathrm{min}^{-1}$ at time, $t$, in minutes. The maximum volume of biogas occurs when the rate is equal to zero. By equating Equation (12) to zero and solving, the result is as per Equation (13):

$$
t_{\max }=\frac{A_{o}^{0.006}}{0.006 k_{a v}}
$$

Equation (13) gives the time at which maximum biogas volume occurs. Furthermore, the approximate time, $t_{1 / 2}$, for half of the initial substrate to biodegrade, called half-life can be obtained as per Equation (14).

$$
t_{1 / 2}=\frac{A_{o}^{0.006}}{0.012 k_{a v}}
$$

\section{Data Presentation and Discussion}

\subsection{Model Equations and Parameters}

The arithmetic average kinetic order and rate constant obtained were 0.994 and $0.3093 \mathrm{~mol}^{0.006} \cdot$ day $^{-1}$, respectively. These were compared with kinetic orders and rate constants from other researches as shown in Table 7. From this table, the zero and first orders were used by other researchers and not the second and third orders. Secondly, the kinetic order of 0.994 obtained in this research is close to the first order used by most other researchers. It can also be seen that different substrate materials, namely, cow dung, pig dung, poultry excreta, olive mill waste and hospital waste were used by different researchers while this research used food residues mixed with fruit wastes. All these and the results indicate that the kinetic order of USW biodegradation processs can be zero, first, close to first or both zero and first orders depending on the substrate material under investigation and the conditions of biodegradation process. This can be attributed to the type, complexity, and nature of SW containing the biodegrading organic matter. Since this research was done under a $\mathrm{pH}$ range of 6 to 8 , the kinetic order obtained being close to first order kinetics is appropriate and suitably used to model the kinetic equations of the biodegradation process under study. In conclusion, the rate constant was slightly higher than that of other substrate materials indicating that food residues mixed with fruit waste gave a slightly higher biodegradation rate than that obtained using pig dung, cow dung, poultry, etc., used by other researchers to generate biogas.

Table 7. A comparison of rate orders and rate constants.

\begin{tabular}{lllll}
\hline Name & $\begin{array}{l}\text { This } \\
\text { work }\end{array}$ & $\begin{array}{l}\text { Kirchmann and } \\
\text { Bernal (1997) }\end{array}$ & $\begin{array}{l}\text { Parades } \text { et al. Wang et al. } \\
(2002)\end{array}$ & $\begin{array}{l}\text { We04) } \\
(2004\end{array}$ \\
\hline $\begin{array}{l}\text { Average } \\
\text { kinetic } \\
\text { order }\end{array}$ & 0.994 & $\begin{array}{l}\text { Zero and } \\
\text { first order }\end{array}$ & First order & $\begin{array}{l}\text { Zero and } \\
\text { first }\end{array}$ \\
$\begin{array}{l}\text { Average } \\
\text { rate } \\
\text { constant } \\
\text { kav }\end{array}$ & $\begin{array}{l}0.3093 \\
\mathrm{~mol}^{0.006} \cdot \text { day }^{-1}\end{array}$ & $\begin{array}{l}\text { (cow dung), } \\
\text { 0.131 (pig dung) } \\
\text { and 0.093 } \\
\text { (poultry excreta) }\end{array}$ & $\begin{array}{l}0.0181 \text { day }^{-1} \\
\text { (olive mill }\end{array}$ & $\begin{array}{l}0.0018 \text { day }^{-1} \\
\text { (hospital } \\
\text { waste), first } \\
\text { order. }\end{array}$ \\
\hline
\end{tabular}




\subsection{Effect of Substrate Weight and Residence Time on Cumulative Volume}

Figures 3 and 4 show the variation of biogas rate and cumulative volume, respectively, with substrate weight and residence time. From the figures the biogas rate and cumulative volume increase with substrate weight. The biogas rate and cumulative volume at 2 minutes sampling time are almost doubled when the substrate weight doubles from 2 to $4 \mathrm{~kg}$ for batch one, 2.15 to $4.30 \mathrm{~kg}$ for batch two and 2.25 to $4.5 \mathrm{~kg}$ for batch three. These values go up almost by three times when substrate weight triples. For example, at 1 day residence time and for 2 minutes sampling time of batch one, the cumulative volume is $2.5 \mathrm{ml}$ for the $2 \mathrm{~kg}$ substrate weight. This volume becomes about $5 \mathrm{ml}$ when the substrate weight is increased to $4 \mathrm{~kg}$ and it is about $7 \mathrm{ml}$ when the substrate weight triples to $6 \mathrm{~kg}$.

This implies that increasing substrate weight increases volume of gas generated. This observation agrees well with research findings by Rao, Baral, Dey and Mutnuri 2010 [5] who found that biogas generation directly depends on organic loading rates. Increasing organic loading rates increases the amount of biogas generated. On the whole, the cumulative gas volume increases with weight of substrate material at all residence times. Therefore, in order to generate a high volume of biogas the weight of substrate material has to be increased.

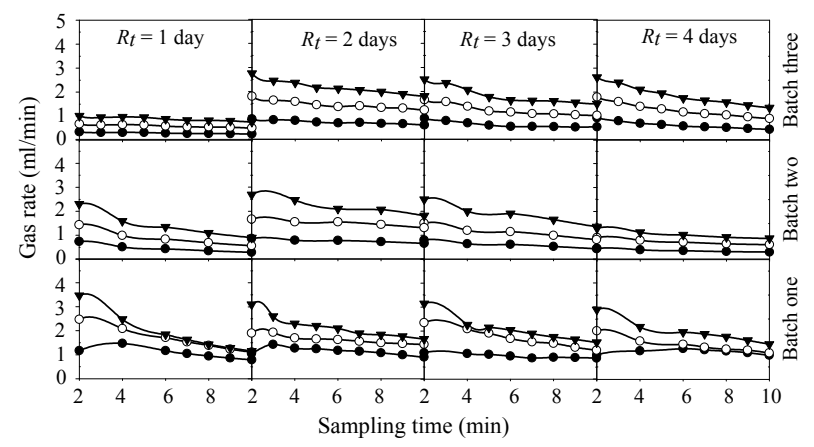

Figure 3. Variation of biogas rate with substrate weight and residence time.

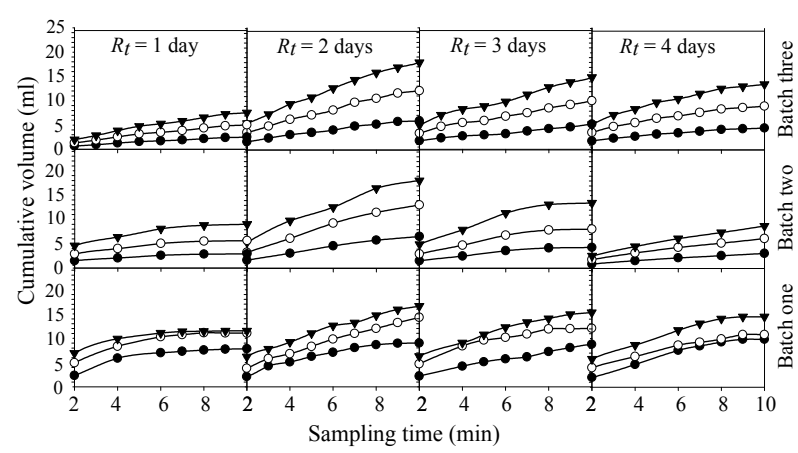

Figure 4. Variation of cumulative volume with substrate weight and residence time.
Secondly, from the figures it can also be seen that initially the cumulative volume increases with residence time and generally declines after 2 days residence time for all batches. This implies that the longer the residence time, the lower the increment in cumulative volume of gas generated for a given sampling time. Therefore, for high volume of biogas generation at longer residence time, fresh substrate material should be added to the bioreactor cell. Furthermore, the figures also show that at high sampling time of 6 minutes and above, the biogas rate and cumulative volume are generally constant, especially for low substrate weight. This indicates that the rate of gas generation decreases with sampling time and residence time. The fairly constant biogas rates and cumulative volume at high sampling time can be attributed to the increase in gas pressure which ultimately has a negative impact on biogas production. High pressures in the bioreactor cell inhibit biodegradation reaction leading to the almost constant biogas rate and cumulative volume at 6 minutes and above of sampling time. This implies that for continuous biodegradation and gas generation, the already generated biogas should be evacuated from the bioreactor space above the SW material in order to reduce bioreactor cell pressure and foster subsequent biogas production.

\subsection{Model Validation}

In order to validate the model equations the amount of biogas generated experimentally was measured and compared with that calculated using Equation (11). Figures 5-7 show a comparison of cumulative volume of biogas obtained using the model equation and that determined experimentally for batches one, two and three, respectively. The three figures show the effect of initial amount of substrate weight on the cumulative volume of biogas. They also show the effect of residence time on the deviations between experimental and model values. From these figures, the deviation between model and experimental data is discussed. First, the residence time has negligible impact on variations between model and experimental data for all values of initial substrate weight. This implies that the deviation between model and experimental data is negligible for different residence times at a given initial substrate weight.

This is because the almost constant substrate weight does not have an impact on the quantity or volume of biogas generated at different residence times, other factors of $\mathrm{pH}$ and temperature remaining constant. Therefore, the mathematical model can predict the experimental data of the same substrate weight at different residence times within experimental error. This means a high reproducibility of model data for the same initial substrate weight. 


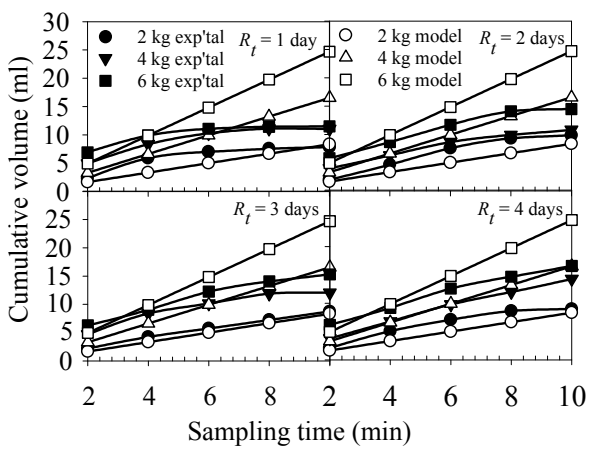

Figure 5. Comparison of model and experimental data for batch one.

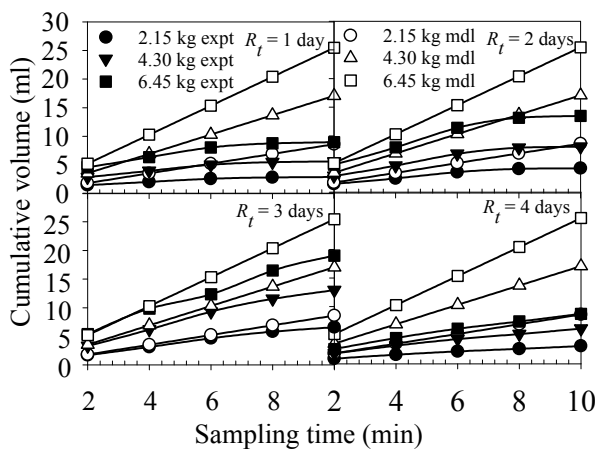

Figure 6. Comparison of model and experimental data for batch two.

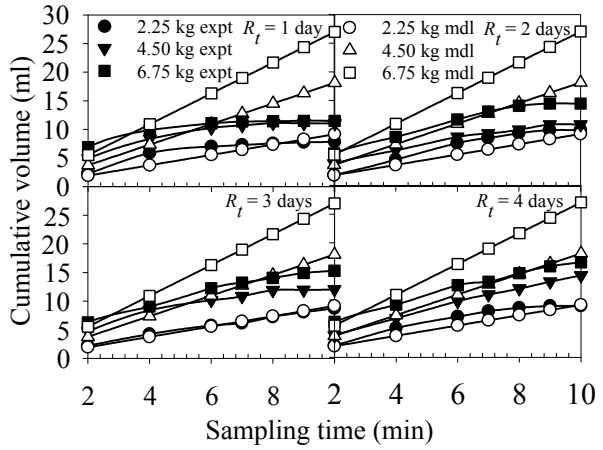

Figure 7. Comparison of model and experimental data for batch three.

Secondly, the initial weight of substrate has a direct impact on the variation between model and experimental data. This implies that increasing initial amount of substrate increases the deviations between model and experimental data. This can be attributed to the increase in cumulative volume of biogas generated as a result of increase in substrate weight. This increase in cumulative volume causes a corresponding pressure increase in bioreactor cell which suppresses subsequent generation of biogas, resulting in little or no increment in quantity of total cumulative volume of experimental data. Eventually a high variation between model and experimental data is observed. Thus, for the mathematical model to predict well the experimental data, the biogas generated should not be allowed to accumulate in the bioreactor cell such that pressure increases which reduce subsequent gas generation do not occur. This results in high predictability of experimental data.

Furthermore, the deviation between model and experimental data of cumulative volume of biogas was observed to be minimal for the low SW weight throughout the sampling time. This is because the small substrate weight generates small volume of biogas and therefore low pressures which do not have great impact on subsequent biogas generation. Consequently at low pressures the experimental data do not vary so much from model data, enhancing the reliability of model data. Beyond 6 minutes of sampling time and at high SW weight the deviations were extraordinarily high. This can be attributed to high cumulative volume of biogas caused by long sampling time and high substrate weight, resulting in reduced accuracy of the model data. Generally, the model and experimental data agreed most with ANOVA, $p=0.0000063$ (Table 8) and least with ANOVA, $p=0.21$ (Table 9). The reproducibility of model data is high for different residence times at constant substrate weight. The predictability and reliability are high with low substrate weight while the accuracy of the model data is reduced with high substrate weight and longer sampling time.

\section{Conclusion}

Using initial rate method the arithmetic average values of kinetic order and rate constant obtained were consistent with values assumed and used in other researches in literature. The rate constant for food residues mixed with fruit waste was slightly higher than that of other substrate

Table 8. Statistical significance of batch one, experiment 1 at 3 days residence time.

\begin{tabular}{ccccc}
\hline $\begin{array}{c}\text { Source of } \\
\text { Variation }\end{array}$ & $d f$ & $F$ & P-value & F crit \\
\hline Rows & 4 & 688.1551 & $6.31 \mathrm{E}-06$ & 705.7732 \\
Columns & 1 & 51.20627 & 0.002018 & 996.6675 \\
Error & 4 & & & \\
Total & 9 & & & \\
\hline
\end{tabular}

Table 9. Statistical significance of batch one, experiment 3 at 1 day residence time.

\begin{tabular}{ccccc}
\hline $\begin{array}{c}\text { Source of } \\
\text { Variation }\end{array}$ & df & F & $p$-value & F crit \\
\hline Rows & 4 & 2.384484 & 0.21031 & 2.3873 \\
Columns & 1 & 2.818574 & 0.16848 & 2.2258 \\
Error & 4 & & & \\
Total & 9 & & & \\
\hline
\end{tabular}


materials implying a slightly higher biodegradation rate than that obtained using pig dung, cow dung, poultry, etc., used by other researchers to generate biogas. This is important considering renewable energy sources for improved efficiencies and yield. The cumulative gas volume and gas generation rate increase with weight of substrate material at all residence times. In order to generate a high volume of biogas the weight of substrate material has to be increased. Also, for high biogas volume and high generation rate at longer residence time, fresh substrate material should be added to the bioreactor cell and for continuous biodegradation and gas generation, the already generated biogas should be removed from the bioreactor in order to enable more biogas production. Increasing the substrate weight increased the absolute deviation, absolute mean and standard deviations, attributed to the increase in biogas pressure caused by cumulative gas volume in the manometer. The longer the residence time the lower the absolute deviation, absolute mean and standard deviations, attributing to the low gas pressure due to low cumulative volume. The model predicted well the experimental data for low substrate weight at all residence times and for high substrate weight at longer residence time. For the model which has predicted well the experimental data at higher substrate weight and shorter residence time, the biogas generated should have been removed from the bioreactor cell immediately when it is formed. It would be helpful to pursue further research about the study and experimental design considering detaching the cumulative volume measuring unit from the bioreactor cell thereby eliminating biogas accumulation within the bioreactor cell.

\section{Acknowledgements}

The success of this work has been made possible with financial assistance from Kyambogo University, Uganda and University of Dar es Salaam, Tanzania.

\section{REFERENCES}

[1] OECD/IEA, "World Energy Outlook, International Energy Agency," OECD/IEA, Paris, 2006.

[2] OECD/IEA, "Working Together to Ensure Reliable, Affordable and Clean Energy, International Energy Agency," 2012,

[3] P. Weiland, "Biogas Production: Current State and Perspectives," Applied Microbiology and Biotechnology, Vol. 85 , No. 4, 2010, pp. 849-860. doi:10.1007/s00253-009-2246-7

[4] D. Elango, M. Pulikesi, P. Baskaralingam, V. Ramamurthi and S. Sivanesan, "Production of Biogas from Municipal Solid Waste with Domestic Sewage," Journal of Hazardous Materials, Vol. 141, No. 1, 2007, pp. 301304. doi:10.1016/j.jhazmat.2006.07.003
[5] P. V. Rao, S. S. Baral, R. Dey and S. Mutnuri, "Biogas Generation Potential by Anaerobic Digestion for Sustainable Energy Development in India," Renewable and Sustainable Energy Reviews, Vol. 14, No. 7, 2010, pp. 2086-2094. doi:10.1016/j.rser.2010.03.031

[6] P. Sosnowski, A. Wieczorek and S. Ledakowicz, “Anaerobic Co-Digestion of Sewage Sludge and Organic Fraction of Municipal Solid Wastes," Advances in Environmental Research, Vol. 7, No. 3, 2003, pp. 609-616. doi:10.1016/S1093-0191(02)00049-7

[7] P. Sosnowski, A. Klepacz-Smolka, K. Kaczorek and S. Ledakowicz, "Kinetic Investigations of Methane CoFermentation of Sewage Sludge and Organic Fraction of Municipal Solid Wastes," Bioresource Technology, Vol. 99, No. 13, 2008, pp. 5731-5737. doi:10.1016/j.biortech.2007.10.019

[8] K. Braber, "Anaerobic Digestion of Municipal Solid Waste: A Modern Waste Disposal Option on the Verge of Breakthrough," Biomass and Bioenergy, Vol. 9, No. 1-5, 1995, pp. 365-376. doi:10.1016/0961-9534(95)00103-4

[9] A. Ambulkar and A. Shekdar, "Prospects of Biomethanation Technology in the Indian Context: A Pragmatic Approach," Resources, Conservation and Recycling, Vol. 40, No. 2, 2004, pp. 111-128.

doi:10.1016/S0921-3449(03)00037-5

[10] Q. Wang, “Aspects of Pretreated Hospital Waste Biodegradation in Landfills," Department of Mechanical Engineering, University of Duisburg-Essen, Essen, 2004.

[11] G. Lastella, C. Testa, G. Cornacchia, M. Notornicola, F. Voltasio and V. K. Sharma, "Anaerobic Digestion of Semi-Solid Organic Waste: Biogas Production and Its Purification," Energy Conversion and Management, Vol. 43, No. 1, 2002, pp. 63-75. doi:10.1016/S0196-8904(01)00011-5

[12] F. García-Ochoa, V. Santos, L. Naval, E. Guardiola and B. Lopez, "Kinetic Model for Anaerobic Digestion of Livestock Manure," Enzyme and Microbial Technology, Vol. 25, No. 1-2, 1999, pp. 55-60. doi:10.1016/S0141-0229(99)00014-9

[13] I. Tosun, M. Gönüllü, E. Arslankaya and A. Günay, "Co-Composting Kinetics of Rose Processing Waste with Organic Fraction of Municipal Solid Waste," Bioresource Technology, Vol. 99, No. 14, 2008, pp. 6143-6149. doi:10.1016/j.biortech.2007.12.039

[14] T. Sreekrishnan, S. Kohli and V. Rana, "Enhancement of Biogas Production from Solid Substrates Using Different Techniques-A Review," Bioresource Technology, Vol. 95, No. 1, 2004, pp. 1-10.

doi:10.1016/j.biortech.2004.02.010

[15] V. Vavilin, S. Rytov, L. Lokshina, S. Pavlostathis and M. Barlaz, "Distributed Model of Solid Waste Anaerobic Digestion: Effects of Leachate Recirculation and $\mathrm{pH}$ Adjustment," Biotechnology and Bioengineering, Vol. 81, No. 1, 2003, pp. 66-73. doi:10.1002/bit.10450

[16] F. G. Pohland, "Sanitary Landfill Stabilization with Leachate Recycle and Residual Treatment, Epa," Civil Engineering, Vol. 106, No. 6, 1975, pp. 1057-1069

[17] H. Kirchmann and M. Bernal, "Organic Waste Treatment and C Stabilization Efficiency," Soil Biology and Bio- 
chemistry, Vol. 29, No. 11-12, 1997, pp. 1747-1753. doi:10.1016/S0038-0717(97)00065-5

[18] C. Paredes, M. Bernal, J. Cegarra and A. Roig, "BioDegradation of Olive Mill Wastewater Sludge by Its Co-Composting with Agricultural Wastes," Bioresource Technology, Vol. 85, No. 1, 2002, pp. 1-8. doi:10.1016/S0960-8524(02)00078-0

[19] M. Baptista, F. Antunes, M. S. Gonçalves, B. Morvan and A. Silveira, "Composting Kinetics in Full-Scale Mechanical-Biological Treatment Plants," Waste Management, Vol. 30, 2010, pp. 1908-1921.

[20] R. K. Dereli, M. E. Ersahin, H. Ozgun, I. Ozturk and A. F. Aydin, "Applicability of Anaerobic Digestion Model No. 1 (Adm1) for a Specific Industrial Wastewater: Opium Alkaloid Effluents," Chemical Engineering Journal, Vol. 165, No. 1, 2010, pp. 89-94. doi:10.1016/j.cej.2010.08.069
[21] A. Barthakur, M. Bora and H. D. Singh, "Kinetic Model for Substrate Utilization and Methane Production in the Anaerobic Digestion of Organic Feeds," Biotechnology Progress, Vol. 7, 1991, pp. 369-376. doi: $10.1021 / \mathrm{bp} 00010 \mathrm{a} 012$

[22] J. Siles, M. Martin, A. Chica and R. Borja, "Kinetic Modelling of the Anaerobic Digestion of Wastewater Derived from the Pressing of Orange Rind Produced in Orange Juice Manufacturing," Chemical Engineering Journal, Vol. 140, No. 1-3, 2008, pp. 145-156. doi:10.1016/i.cej.2007.09.026

[23] K. P. Singh, S. Gupta, A. K. Singh and S. Sinha, "Optimizing Adsorption of Crystal Violet Dye from Water by Magnetic Nanocomposite Using Response Surface Modeling Approach," Journal of Hazardous Materials, Vol. 186, 2011, pp. 1462-1473. 